\title{
Airway responsiveness: associated features in infants with recurrent respiratory
} symptoms

\author{
A. Kotaniemi-Syrjänen, L.P. Malmberg, A.S. Pelkonen, K. Malmström and M.J. Mäkelä
}

ABSTRACT: Increased airway responsiveness (AR) is one of the main pathophysiological manifestations of asthma. The present study aimed to define the clinical features associated with increased AR in infants with recurrent lower respiratory tract symptoms.

AR was evaluated by performing a novel dosimetric methacholine challenge test.

Increased AR to methacholine, defined as a methacholine dose of $\leqslant 0.90 \mathrm{mg}$ producing a $\mathbf{4 0 \%}$ fall (PD40) in the maximal flow at functional residual capacity ( $V^{\prime}$ max,FRC), was associated with atopy (odds ratio (OR) 4.1 ; $95 \%$ confidence interval (Cl) 1.3-13.3), a history of physicianconfirmed wheezing with respiratory syncytial virus (OR 32.9; $95 \% \mathrm{Cl} 2.5-428.8$ ) or of a nonspecified aetiology (OR 4.9; $95 \% \mathrm{Cl} 1.1-22.5$ ), functional residual capacity z-score $\geqslant 2$ (OR 36.8; 95\% Cl 2.9-472.6), and $V^{\prime} \max$,FRC z-score (OR 0.5; 95\% Cl 0.2-0.9) at baseline, when compared with infants with only mild or no responsiveness to methacholine (PD40 V'max,FRC $>0.90 \mathrm{mg}$ ).

In conclusion, in recurrently symptomatic infants, increased airway responsiveness is associated with reduced baseline lung function, an atopic trait of the child, a history of physician-confirmed wheeze and viral aetiology of wheeze. Future intervention studies are needed to confirm the role of airway responsiveness in respiratory morbidity during infancy.

KEYWORDS: Airways hyperreactivity, bronchial provocation tests, infant, methacholine chloride, pulmonary function tests

ncreased airway responsiveness (AR), together with persistent airway inflammation, is one of

the main pathophysiological manifestations of asthma [1]. Increased AR to pharmacological stimuli, such as methacholine or histamine, can be demonstrated in almost all steroid-naïve asthmatics $[2,3]$ and, therefore, tests to measure AR are commonly used as part of the clinical assessment of adults and schoolchildren with a suspicion of asthma. In contrast, the pathophysiology of increased AR is poorly understood in infants, and there are contradictory data on how increased AR is related to actual symptoms and clinical characteristics during infancy. Most infants respond to bronchoconstrictor agonists unless dosages have been corrected for their body size [4-6], which complicates the assessment of AR at this age. Previous reports have suggested that these responses are independent of lower respiratory tract symptoms, including wheezing $[5,7]$.
However, there is some evidence that increased AR during infancy is related to the development of asthma in later childhood. In an Australian follow-up study [8], increased AR to histamine at age 1 month in healthy infants was found to be associated with asthma, decreased lung function and lower respiratory tract symptoms at age 6 yrs. Even at age 11 yrs, AR was reported to be increased in those children with both increased $\mathrm{AR}$ and reduced lung function at age 1 month [9]. Additionally, in children with a history of bronchiolitis or wheezy bronchitis, increased AR to methacholine was found to be associated with persistent wheezing and the development of asthma in a 10-yr follow-up [10].

Simple clinical characteristics have also been shown to predict the subsequent development of asthma in young children with reasonable accuracy [11]. Based on the Tucson Children's

Presented in part as a poster at the 15th European Respiratory Society Annual Congress, Copenhagen, Denmark, September 17-21, 2005. The abstract related to the poster is published in Eur Respir J 2005; 26: Suppl. 49, 675s. 
Respiratory Study, CASTRO-RODRíGUEZ et al. [11] proposed a clinical index including several predictive features, such as frequent wheezing during the first 3 yrs of life, a parental history of asthma, atopy and eosinophilia.

The current authors hypothesised that the clinical features associated with the increased risk of the development of asthma are the same as those associated with increased AR during infancy. Therefore, the aim of the present study was to clarify the relationship between increased AR and several clinical characteristics and lung function parameters in a cohort of infants with recurrent lower respiratory tract symptoms, in order to identify those infants with increased AR by their clinical characteristics. AR was measured with a novel dosimetric methacholine challenge method designed for infants.

\section{METHODS}

\section{Study subjects}

In total, 199 consecutive children who had been referred to a tertiary centre (Dept of Allergology, Helsinki University Central Hospital, Helsinki, Finland) for investigation of recurrent lower respiratory tract symptoms (including wheeze, cough, sputum production or dyspnoea) underwent lung function and provocation tests as part of their clinical assessment between May 5, 2004 and March 8, 2006. These children constituted part of the recruitment cohort of a prospective intervention study into infant asthma. The intervention study, including the performance of the baseline lung function and bronchial provocation tests during the recruitment phase, was approved by the local ethics committee.

Methacholine challenge could not be performed in 47 children due to severe baseline obstruction (flow limitation during tidal breathing and/or resting dyspnoea). In 39 children, technical difficulties (e.g. due to glottic closure, sputum production from upper airways, a leak around the mask during lung function measurements or age $<6$ months) interfered with the performance of the challenge test, and in six children, awakening during the measurements led to discontinuation of the challenge.

The methacholine challenge was successfully performed in 107 infants. Only full-term (gestational age $\geqslant 36$ weeks), steroidfree (for $\geqslant 1$ month prior to testing) or steroid-naïve infants without any symptoms of acute respiratory infection (for $\geqslant 2$ weeks prior to testing) were included in the analyses $(n=90)$. The data from these 90 infants comprise the material of the present study.

All the tests were performed as part of the clinical assessment of the children, and were conducted after informed consent to perform these tests had been received from the parents. After lung function testing and the methacholine challenge, some of the children were recruited into an intervention study of infant asthma, and a further written consent to participate in the study was obtained from the parents of these children. In addition, parents of the children who were not eligible for the intervention study were asked for their consent for the use of lung function and challenge test results for research purposes.

At the hospital visit, the clinical data were collected prospectively from the medical records of the hospital with a standardised form designed for the intervention study (including data on the occurrence of symptoms, medication, hospital admissions and history of respiratory syncytial virus (RSV) bronchiolitis).

\section{Lung function tests}

Lung function tests were performed according to the protocol used at Helsinki University Central Hospital, as follows: infants were sedated with orally administered chloral hydrate (75$100 \mathrm{mg} \cdot \mathrm{kg}^{-1}$; maximum dose 1,000 mg) prior to testing. During lung function testing, the infant was lying supine with the head supported in the midline and the neck slightly extended to minimise airway or glottic obstruction. All measurements were recorded and calculations performed with commercial paediatric pulmonary function equipment (Babybody Masterscreen; Jaeger $\mathrm{GmbH}$, Würzburg, Germany). Functional residual capacity (FRC) was measured by total body plethysmography, as described in detail previously [12]. The maximal partial expiratory flow volume (PEFV) was obtained using the rapid thoracic compression technique (i.e. tidal squeeze) by rapid inflation of a thoracoabdominal jacket at the beginning of expiration [13]. The jacket was wrapped around the infant's chest and abdomen with the arms extended outside the jacket. Flow was measured at the infant's nose and mouth with a pneumotachometer attached to a face mask. A rim of silicone putty was applied around the mouth and nose and to the face mask to provide an airtight seal. The compression pressure was progressively increased until there was no further increase in forced expiratory flow at FRC ( $V^{\prime}$ max,FRC), and the mean $V^{\prime}$ max,FRC of three technically acceptable PEFV curves obtained at that compression pressure was recorded. PEFV curves were considered technically acceptable when the peak flow occurred prior to expiring $50 \%$ of the tidal volume, there were no transients in the PEFV curve in the region of FRC, and forced expiration lasted long enough to allow recording of flow at FRC.

The baseline lung function results were expressed as z-scores, which are equivalent to the number of standard deviations by which the measured value deviates from the length- and sexcorrected reference value [14, 15].

All infants were studied when they were free from current signs of respiratory infection. $\beta_{2}$-Agonists were withheld for $12 \mathrm{~h}$ prior to lung function and challenge tests.

\section{Methacholine challenge}

For the dosimetric methacholine challenge, a calibrated nebuliser (Salter Labs 8900, Arvin, CA, USA) was connected to an automatic, inhalation-synchronised dosimeter (Spira Electro II; Spira Respiratory Care Center Ltd, Hämeenlinna, Finland) [16]. The dosimeter was set to be triggered by an inhaled volume of $20 \mathrm{~mL}$ in each breath, after which a methacholine chloride dose of $50 \mu \mathrm{g}$ was nebulised within $0.2 \mathrm{~s}$ in an air volume of $25 \mathrm{~mL}$. The dosimeter incorporates an indicator for inspiratory flows and volumes, which were carefully monitored during the administration of methacholine to ensure sufficient tidal flows $\left(>100 \mathrm{~mL} \cdot \mathrm{s}^{-1}\right)$ and volumes $(>50 \mathrm{~mL})$. By calculating the number of breaths with nebulised methacholine, a rapid dosage scheme with four noncumulative dose steps was applied $(0.1,0.3,0.9$ and $1.8 \mathrm{mg})$, with $V^{\prime}$ max,FRC being recorded after each dose. 
At each phase, the applied compression pressure was the same as that which achieved the highest flows at baseline. There were two end-points in the challenge test: a fall $\geqslant 40 \%$ in $V^{\prime}$ max,FRC or reaching the maximal dose of methacholine.

The provocative dose of methacholine causing a $40 \%$ fall in $V^{\prime}$ max,FRC (PD40 $V^{\prime}$ max,FRC) was determined from the doseresponse curves. In cases where the maximal dose was reached and PD40 $V^{\prime}$ max,FRC could not be determined from the doseresponse curves, PD40 $V^{\prime}$ max,FRC was, for statistical purposes, defined as twice the highest dose of methacholine, $3.60 \mathrm{mg}$.

During lung function measurements and the challenge test, oxygen saturation and cardiac frequency were continuously monitored with a pulse oximeter (Biox 3700e; Ohmeda, Louisville, KY, USA). Following the challenge test, the children received inhaled salbutamol $\left(0.6 \mathrm{mg}, 0.1 \mathrm{mg} \cdot\right.$ dose $^{-1}$; Ventoline Evohaler ${ }^{\circledR}$; GlaxoSmithKline, Middlesex, UK) via Nebunette ${ }^{\circledR}$ (AstraZeneca, Sǒdertǎlje, Sweden), and the measurement of $V^{\prime}$ max,FRC was repeated $15 \mathrm{~min}$ after the salbutamol inhalation.

\section{Skin-prick tests}

Sensitisation to common food and/or inhalant allergens, e.g. egg white, cow's milk, wheat, soy bean, cod, shrimp, peanut, birch pollen, timothy grass pollen, dog epithelial dander, cat epithelial dander and the house dust mite Dermatophagoides pteronyssinus, was tested by skin-prick tests (SPT). SPT positivity was defined as a wheal with a diameter of $\geqslant 3 \mathrm{~mm}$ [17] against at least one of the tested allergens. Physiological saline was applied as a negative control.

\section{Definitions}

A history of wheezing was defined as at least one episode of physician-confirmed wheeze. A family history of asthma was regarded as physician-diagnosed asthma in a first degree relative. A family history of allergy was regarded as physiciandiagnosed allergy in a first degree relative. Food allergy was defined as a diagnosis confirmed by a positive food challenge. Atopic eczema was defined as a current diagnosis made by a paediatrician. Atopy was defined as the presence of atopic eczema and/or SPT positivity.

AR to methacholine was divided into three categories: increased (PD40 $V^{\prime}$ max,FRC $\leqslant 0.90 \mathrm{mg}$ ), mild (PD40 $V^{\prime}$ max,FRC $>0.90$ but $<3.60 \mathrm{mg}$ ), or no (PD40 $V^{\prime} \max$, FRC $3.60 \mathrm{mg}$ ) responsiveness. The categorisation based on the aforementioned dose steps applied in the dosimetric methacholine challenge. For statistical purposes, the groups of mild and no responders were combined.

RSV bronchiolitis was defined as a wheezing lower respiratory tract illness with RSV infection confirmed by antigen detection (Light Diagnostics ${ }^{\mathrm{TM}}$ Respiratory DFA Viral Screening and Identification Kit; Chemicon International Inc., Temecula, CA, USA) in a nasopharyngeal aspirate during an emergency consultation.

\section{Statistics}

To evaluate the statistical differences between the groups, Chisquared test or Fisher's exact test (if the expected frequency for any cell was less than five) were used for dichotomous variables, and Mann-Whitney U-test was used to analyse continuous or ordinal variables. Correlations between variables were analysed using Pearson's correlation test (continuous variables) or Spearman's rank correlation test (ordinal variables). Logistic regression analysis was performed to calculate the adjusted odds ratios and related $95 \%$ confidence intervals in multivariate settings. Two-tailed tests were used in all analyses. A value of $\mathrm{p}<0.05$ was considered statistically significant.

\section{RESULTS}

The baseline characteristics of the study children are presented in table 1 . Most infants were Caucasian $(n=88 ; 98 \%)$. None of the children had major congenital cardiac or other malformations. The median duration of respiratory symptoms was 7 months (range 2-18 months). A family history of asthma or allergy was present in $78(87 \%)$ children; in the majority, this was a maternal history of asthma or allergy, which was present in $55(61 \%)$ infants. In total, $36(40 \%)$ children had atopic eczema or were SPT-positive and $11(12 \%)$ children had a history of proven RSV bronchiolitis, which had been diagnosed at a median (range) 4 (1-20) months earlier. In addition, there were 12 children with negative results in RSV antigen testing during a wheezing episode, and 48 children with a history of wheeze confirmed by a physician with no attempts of viral detection made.

Data on baseline lung function are presented in table 2. Median coefficients of variation for FRC and $V^{\prime}$ max,FRC were 2.6 and $4.0 \%$, respectively. At baseline, there was a weak but positive correlation $(\mathrm{r}=0.223 ; \mathrm{p}=0.035)$ between FRC and $V^{\prime}$ max,FRC, expressed as z-scores.

During the methacholine provocation, the median changes in $V^{\prime}$ max,FRC and oxygen saturation were -51 and $-3 \%$, respectively. At its lowest, oxygen saturation varied $86-97 \%$ (median $93 \%$ ). There were three children with a fall of oxygen saturation to $<90 \%$. None of these three children had reduced lung function at baseline and thus the fall in saturation could not have been anticipated. In each case, the fall in saturation was transient, improving in a few minutes. No serious adverse events were encountered, and there was a rapid improvement in oxygen saturation and lung function after administration of bronchodilator in all but two infants who exhibited prolonged bronchoconstriction (15 min after the salbutamol inhalation $V^{\prime}$ max,FRC was still $>40 \%$ lower than at baseline) and required an additional salbutamol inhalation. All the infants were discharged from the hospital as clinically healthy and stable after a follow-up of $2-5 \mathrm{~h}$.

AR to methacholine with regard to baseline characteristics is presented in table 3 , and with regard to baseline lung function parameters in table 4 . AR to methacholine was considered increased in $56(62 \%)$ children and mild in 14 (16\%) children; $20(22 \%)$ children did not respond significantly to the maximum dose of methacholine.

Children with a history of RSV bronchiolitis $(n=11)$ had a median (range) PD40 $V^{\prime}$ max,FRC of $0.43(0.11-1.13) \mathrm{mg}$, and those with a history of wheezing due to a nonspecified aetiology $(n=60)$ had a PD40 $V^{\prime}$ max,FRC of $0.62(<0.10-3.60) \mathrm{mg}$ $(\mathrm{p}=0.003$ and $\mathrm{p}=0.006$, respectively, with regard to PD40 $V^{\prime}$ max,FRC of children with no history of wheezing $(n=22$; 3.60 (0.10-3.60) mg); fig. 1). The difference in PD40 $V^{\prime}$ max,FRC between the children with a history of RSV bronchiolitis and those with a history of wheezing due to a nonspecified 
TABLE 1 Baseline characteristics of the study children

\begin{tabular}{|c|c|}
\hline Baseline characteristics & \\
\hline Subjects & 90 \\
\hline Age months & $14.9(6.8-25.8)$ \\
\hline Males/females & $68 / 22(76 / 24)$ \\
\hline Gestational age ${ }^{\#}$ weeks & $40.00(36.57-42.43)$ \\
\hline Birth weight $\mathbf{g}$ & $3585(2040-4600)$ \\
\hline Main complaints & \\
\hline Cough & $50(56)$ \\
\hline Wheeze & $13(14)$ \\
\hline Dyspnoea & $17(19)$ \\
\hline Sputum production & $10(11)$ \\
\hline Duration of symptoms months & $7(2-18)$ \\
\hline History of wheezing & $71(79)$ \\
\hline 1 episode of wheezing & $18(20)$ \\
\hline 2 episodes of wheezing & $24(27)$ \\
\hline$\geqslant 3$ episodes of wheezing & $29(32)$ \\
\hline Hospital admission for wheezing & $24(27)$ \\
\hline History of RSV bronchiolitis ${ }^{+}$ & $11(12)$ \\
\hline Family history of asthma ${ }^{5}$ & $48(53)$ \\
\hline Family history of allergy ${ }^{f}$ & $75(83)$ \\
\hline Atopic eczema ${ }^{\# \#}$ & $28(31)$ \\
\hline Skin-prick test positive & $20(22)$ \\
\hline Atopy $^{++}$ & $36(40)$ \\
\hline Food allergy ${ }^{\S \S}$ & $21(23)$ \\
\hline Exposure to tobacco smoke & $31(34)$ \\
\hline Maternal smoking & $22(24)$ \\
\hline Furry animals at home & $22(24)$ \\
\hline
\end{tabular}

Data are presented as $n, n(\%)$ and median (range). RSV: respiratory syncytial

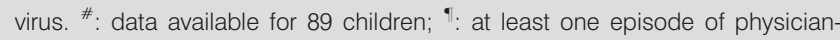
confirmed wheeze; ${ }^{+}$: wheezing lower respiratory tract illness with RSV infection proven by antigen detection; ${ }^{\text {s. }}$ : physician-diagnosed asthma in a first degree relative; ${ }^{f}$ : physician-diagnosed allergy in a first degree relative; ${ }^{\# \#}$ : current diagnosis made by a paediatrician; $"$ " a wheal with a diameter $\geqslant 3 \mathrm{~mm}$ against at least one of the tested allergens; ${ }^{++}$: presence of atopic eczema and/or skinprick test positivity; ${ }^{\S \S}$ : diagnosis confirmed by a positive food challenge.

aetiology was not statistically significant $(p=0.150)$. The number of wheezing episodes was significantly associated with increased AR (table 3); there was a negative correlation between the number of wheezing episodes and PD40 $V^{\prime}$ max,FRC $(\mathrm{r}=-0.310 ; \mathrm{p}=0.003)$.

Atopy, defined as atopic eczema and/or SPT positivity, was also associated with increased responsiveness to methacholine (table 3). In contrast, sex, age, weight, height, birth weight, prematurity, a family history of asthma or allergy, or exposure to tobacco smoke did not have any significant effect on a child's responsiveness to methacholine (data not shown for most of the aforementioned variables).

Maternal smoking was more common in those with a history of RSV bronchiolitis (six (55\%) out of 11 subjects) than in those without such a history $(16(20 \%)$ out of $79 ; p=0.022)$.

There was a positive correlation between $V^{\prime}$ max,FRC z-score and PD40 V'max,FRC ( $r=0.392 ; \mathrm{p}<0.001)$, and the infants with low
TABLE 2 Baseline lung function in 90 study children

Lung function parameters

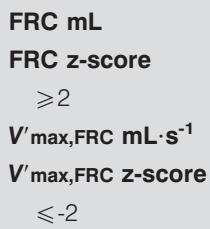

Data are presented as median (range) or $\mathrm{n}$ (\%). FRC: functional residual capacity; V'max,FRC: maximal expiratory flow at functional residual capacity.

lung function (decreased $V^{\prime} \max , \mathrm{FRC}$ ) or signs of hyperinflation (increased FRC) were more prone to exhibit increased AR (table 4).

Table 5 presents the results of the multivariate analyses, showing that atopy, a history of physician-confirmed wheezing and viral aetiology of wheeze were all independently associated with increased AR in recurrently symptomatic infants. In addition to these clinical characteristics, diminished baseline lung function was also associated with increased AR.

\section{DISCUSSION}

The present study found that there were several clinically important features which were significantly associated with

\section{TABLE 3 Airway responsiveness (AR) to methacholine with} regard to baseline characteristics

\begin{tabular}{|c|c|c|c|}
\hline \multirow[t]{2}{*}{ Baseline characteristics } & \multicolumn{2}{|c|}{ AR to methacholine } & \multirow[t]{2}{*}{$p$-value ${ }^{+}$} \\
\hline & Mild or no $\mathrm{AR}^{\#}$ & Increased AR & \\
\hline Age months & $14.2(7.6-25.8)$ & $13.5(6.8-25.4)$ & 0.535 \\
\hline Male & $26(76)$ & $42(80)$ & 0.875 \\
\hline Atopic eczema ${ }^{\S}$ & $6(18)$ & $22(39)$ & 0.032 \\
\hline Skin-prick test positive ${ }^{f}$ & $5(15)$ & $15(27)$ & 0.181 \\
\hline Atopy $^{\# \#}$ & $9(26)$ & $27(48)$ & 0.041 \\
\hline Exposure to tobacco smoke & $13(38)$ & $18(32)$ & 0.555 \\
\hline History of wheezing"ब & $21(62)$ & $50(89)$ & 0.002 \\
\hline RSV aetiology ${ }^{++}$ & 1 (3) & $10(18)$ & $0.003^{\S \S}$ \\
\hline Nonspecified aetiology & $20(59)$ & $40(71)$ & $0.003^{\S \S}$ \\
\hline Wheezing episodes ${ }^{f f}$ & $1(0-5)$ & $2(0-7)$ & 0.009 \\
\hline
\end{tabular}

Data are presented as median (range) and $\mathrm{n}(\%)$. RSV: respiratory syncytial virus. \#: provocative dose of methacholine causing a $40 \%$ fall in forced expiratory flow at functional residual capacity (PD40 V'max,FRC) $>0.90 \mathrm{mg}$ $(n=34) ; ~ \because: P D 40 V^{\prime}$ max,FRC $\leqslant 0.90 \mathrm{mg}(n=56) ;^{+}$: univariate analyses, performed by Chi-squared test or Fisher's exact test (dichotomous variables), or by MannWhitney U-test (continuous variables); ${ }^{\mathrm{s}}$ : current diagnosis made by a paediatrician; $f$ : a wheal with a diameter $\geqslant 3 \mathrm{~mm}$ against at least one of the tested allergens; \#\#: presence of atopic eczema and/or skin-prick test positivity; " ": at least one episode of physician-confirmed wheeze; ${ }^{++}$: RSV infection proven by antigen detection; ${ }^{\S \S}$ : no history of wheezing as a reference; ff: physician-confirmed episodes of wheezing. 


\begin{tabular}{|c|c|c|c|c|}
\hline \multirow{3}{*}{\multicolumn{2}{|c|}{$\begin{array}{l}\text { TABLE } 4 \\
\text { Baseline lung }\end{array}$}} & \multicolumn{3}{|c|}{$\begin{array}{l}\text { Airway responsiveness (AR) to methacholine with } \\
\text { regard to baseline lung function }\end{array}$} \\
\hline & & \multicolumn{2}{|c|}{ AR to methacholine } & \multirow[t]{2}{*}{ p-value ${ }^{+}$} \\
\hline & & Mild or no $\mathrm{AR}^{\#}$ & Increased AR & \\
\hline FRC z-score & & $0.4(-1.5-4.8)$ & $0.3(-1.8-4.8)$ & 0.809 \\
\hline$\geqslant 2$ & & 1 (3) & $13(23)$ & 0.010 \\
\hline$V^{\prime} \max , F R C Z-s$ & sore & $-0.5(-2.7-0.8)$ & $-1.4(-3.0-1.4)$ & 0.002 \\
\hline$\leqslant-2$ & & $3(9)$ & $13(23)$ & 0.083 \\
\hline \multicolumn{5}{|c|}{ 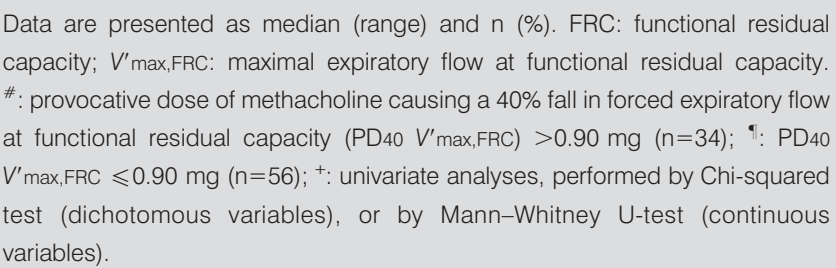 } \\
\hline
\end{tabular}

increased AR in infants and toddlers with recurrent lower respiratory tract symptoms. These features include a history of physician-confirmed wheeze, especially if this was due to RSV infection, atopic characteristics and decreased baseline lung function. Although the present study design differs from earlier studies in the same field $[8,10]$, the results point in the same direction: future intervention studies are needed to confirm the role of AR in respiratory morbidity during infancy. In addition, the infants likely to present with increased AR seemed to have similar clinical features to those associated with symptom persistence and asthma later in childhood.

The study design represents a subset of patients referred to a tertiary centre for further investigation of recurrent lower respiratory tract symptoms within a period of 22 months. Due to the present setting, it is likely that there was a bias with regard to the characteristics of the study subjects; it is reasonable to presume that there was an enrichment of the atopics and those with more troublesome symptoms in these study subjects than would be the case in paediatric patients presenting at primary healthcare units.

For ethical reasons, the present study did not include a control group of healthy children, and thus comparisons of AR had to be performed within the cohort. Therefore, the relative risks for increased AR in various subgroups of the cohort could not be assessed with respect to asymptomatic infants. Predicted values from healthy infants were obtained from studies utilising identical equipment and procedures as used in the current authors' laboratory, and represent infants of similar age and origin (Caucasian); therefore, the present findings and interpretation regarding z-scores are likely to be valid.

A modified and shortened dosimetric protocol was used for methacholine challenge [18]. The method was found to be safe in the present study, although special caution with infants with reduced lung function at the baseline is needed, since two infants displayed prolonged bronchoconstriction after the challenge. Based on this experience, the current authors do not encourage bronchial challenge testing in infants with baseline $V^{\prime}$ max,FRC below a $\mathrm{z}$-score of -2 . Inhalation synchronised

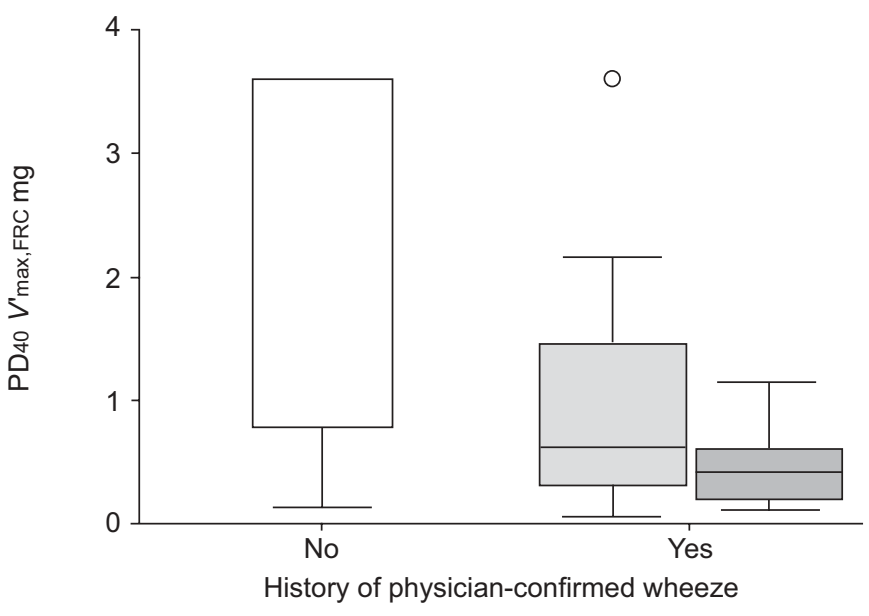

FIGURE 1. Airway responsiveness to methacholine and its relationship to history of wheezing and respiratory syncytial virus (RSV) identification. Methacholine dose producing a $40 \%$ fall in the maximal flow at functional residual capacity (PD40 $V^{\prime}$ max,FRC) was significantly lower in children with a history of RSV bronchiolitis ( $\square ; n=11$, median (range) $0.43(0.11-1.13) \mathrm{mg} ; \mathrm{p}=0.003$ ) and in those with a history of physician-confirmed wheeze due to nonspecified aetiology ( $\square ; n=60$, $0.62(<0.10-3.60) \mathrm{mg} ; \mathrm{p}=0.006)$, compared with those without any episodes of physician-confirmed wheezing $(\square ; n=19,3.60$ (0.10-3.60) mg). There were no differences in PD40 $V^{\prime}$ max,FRC between children with RSV and those with a nonspecified aetiology for wheeze $(p=0.150)$

dosimetry permitted accurate and rapid dosing of the test agonist and determination of AR. At the moment, there is no consensus about the standardisation of bronchial challenge tests in infants, and the comparison of AR between infants and children with different ages and size is difficult due to methodological reasons [6]. The current authors did not make any size correction for the delivered dose, because the design was cross-sectional and the sample rather homogeneous as regards the size of the children. Furthermore, within the sample, there was no association between AR and the dimensions of the infant. Since there is no gold standard PD40 $V^{\prime}$ max,FRC value to indicate an increased AR, an arbitrary value of $0.90 \mathrm{mg}$, based on the doses of methacholine administered in the method of the present study, was chosen as the cut-off value. Although arbitrary, the value was shown to be useful in differentiating between the children with the characteristics usually associated with symptom persistence from those without such features.

Little is known on the mechanisms of AR in infancy. Structural changes in the airways associated with increased contractile force or decreased load to airway narrowing may result in increased AR [19]. However, in the developing lungs of infants, airway-parenchymal interdependence is complex, and the lungs are susceptible to many pre- and post-natal factors [20]. Recently, the current authors found that a thickened basement membrane and eosinophilic airway inflammation, two factors which in older children and adults are typically associated with increased AR, are usually absent in infants with recurrent respiratory symptoms [21]. Reduced baseline lung function was found to be associated with increased AR in infants, as has been observed in infants by other studies [22, 23], and is consistent with findings in older subjects [9]. In the present study, high FRC was also 
TABLE 5 Increased airway responsiveness to methacholine with regard to clinical characteristics and baseline lung function\#

\begin{tabular}{|c|c|c|c|c|}
\hline \multirow[t]{2}{*}{ Clinical characteristics and lung function parameters } & \multicolumn{2}{|c|}{ Model $1^{\circ}$} & \multicolumn{2}{|c|}{ Model $2^{+}$} \\
\hline & OR & $95 \% \mathrm{Cl}$ & OR & $95 \% \mathrm{Cl}$ \\
\hline Age months & 1.0 & $0.9-1.1$ & 1.0 & $0.9-1.1$ \\
\hline Male & 0.6 & $0.2-2.0$ & 0.7 & $0.2-2.6$ \\
\hline Atopy ${ }^{\S}$ & 3.2 & $1.1-9.3$ & 4.1 & $1.3-13.3$ \\
\hline Nonspecified aetiology & 5.6 & $1.7-18.5$ & 4.9 & $1.1-22.5$ \\
\hline FRC $z$-score $\geqslant 2$ & & & 36.8 & $2.9-472.6$ \\
\hline$V_{\text {'max,FRC z-score }}$ & & & $0.5^{++}$ & $0.2-0.9^{++}$ \\
\hline
\end{tabular}

The multivariate analyses were performed by logistic regression; mild or no airway responsiveness to methacholine (methacholine dose producing a $40 \%$ fall in the maximal flow at functional residual capacity $>0.90 \mathrm{mg}$ ) as a reference. OR: odds ratio; Cl: confidence interval; RSV: respiratory syncytial virus; FRC: functional residual capacity; V'max,FRC: maximal flow at functional residual capacity. ${ }^{*}$ : results of the multivariate analyses; " ${ }^{*}$ in model 1 , only clinical characteristics are considered; ${ }^{*}$ : in model 2, baseline lung function data are also included; ${ }^{\text {s: }}$ : presence of atopic eczema and/or skin-prick test positivity; ${ }^{f}$ : at least one episode of physician-confirmed

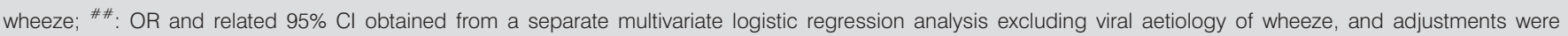
performed for age, sex and atopy in model 1 and for age, sex, atopy, FRC $z$-score $\geqslant 2$, and V'max,FRC $z$-score in model 2 ; " ${ }^{\text {: }}$ : RSV infection proven by antigen detection; ${ }^{++}$: increase in $V^{\prime}$ max,FRC $z$-score reduces airway responsiveness to methacholine.

significantly associated with increased AR. Mechanistically, high FRC should oppose airway narrowing; therefore, the observed association with AR is likely to be due to mechanisms leading to hyperinflation rather than high FRC per se. Notably, both high FRC and low $V^{\prime}$ max,FRC were independent predictors of increased AR. This may be due to biased $V^{\prime}$ max,FRC recordings in cases of elevated FRC, and it indicates that this group of infants with baseline lung function abnormalities may actually consist of two different subcategories, i.e. volume elevators and flow decreasers.

The measurement of $V^{\prime} \max , \mathrm{FRC}$ is, by definition, dependent on the lung volume (i.e. FRC) where the measured flow takes place. Biased $V^{\prime}$ max,FRC values in cases of elevated FRC may partly explain the unexpected positive correlation between FRC and $V^{\prime}$ max,FRC at baseline. Furthermore, methodological problems causing underestimation of lung volumes in infants recovering from bronchiolitis have been previously recognised [24], and may account for the findings in the present series.

The findings of previous follow-up studies suggest that increased AR in early childhood associates with the subsequent occurrence of lower respiratory tract symptoms and asthma up to school age, both in previously healthy [8] and in symptomatic [10] infants and toddlers. Therefore, it may be useful to identify symptomatic infants who exhibit increased AR. Their symptoms are likely to persist, and this may necessitate anti-asthmatic treatment. However, the routine measurement of AR during infancy is not feasible, and cut-off points for provocative concentrations or doses of methacholine determining clinical significance have not been established [25]. Therefore, the infants likely to present with increased AR have to be identified from their clinical characteristics. Although increased AR is an important feature of asthma in adults and older children [1], the relationship between AR, actual respiratory symptoms and clinical presentation is not obvious in infants. Previous reports have suggested that AR is independent of lower respiratory tract symptoms, including wheezing $[5,7]$. The results with a larger cohort found in the present study are at odds with the aforementioned findings, since it was possible to identify several clinical features associated with increased AR in infants with recurrent lower respiratory tract symptoms. These clinical features, i.e. recurrent wheeze and atopy, are rather similar to those listed in a clinical index to define risk of asthma in young children [11].

The long-term outcome of a wheezy infant is also affected by a history of RSV bronchiolitis [26], a family history of asthma [27] or atopy [25], and smoke exposure in infancy [8, 27]. There is little (and contradictory) evidence for the association of these characteristics with increased AR in infancy. The current authors found one controlled study stressing the association of bronchiolitis and increased AR [28]; one cross-sectional study in healthy infants, showing that the family history of asthma and parental smoking were significantly associated with increased AR [29]; and one controlled follow-up study with no association between AR and a history of RSV lower respiratory tract illness or exposure to tobacco smoke [23]. In agreement with the findings of the first mentioned study [28], the current authors observed that a history of physicianconfirmed wheeze was strongly associated with increased AR in the present study setting. Furthermore, it was shown that the AR increased with a growing number of wheezing episodes. In contrast to the earlier findings, the history of RSV bronchiolitis indicated increased AR. In addition, the infants with a smoking mother were more likely to have a history of RSV bronchiolitis. However, as viral studies had been performed as a clinical basis, viral aetiology had been sought only for one-third of the children with a history of physician-confirmed wheeze, and it is thus probable that the role of RSV as a trigger of wheeze was underestimated in the present study. 
At present, there is no evidence that any medical interventions, for instance, could influence the clinical course of AR in at-risk infants [30].

In summary, in addition to poor baseline lung function, several clinical characteristics are associated with increased airway responsiveness in recurrently symptomatic infants. These clinical characteristics, which also resemble the clinical features known to be predictive of the development of childhood asthma, include atopy and a history of physician-confirmed wheeze, especially if due to respiratory syncytial virus bronchiolitis. Future intervention studies are needed to confirm the role of airway responsiveness in respiratory morbidity during infancy.

\section{ACKNOWLEDGEMENTS}

The authors wish to thank T. Rito and H. Punkari (Skin and Allergy Hospital, Helsinki, Finland) for their skill and care with the infants and their parents. The personnel of Spira Respiratory Care Center Ltd (Hämeenlinna, Finland) are acknowledged for their help in the development of the inhalation-synchronised dosimetric equipment used in the methacholine challenge.

\section{REFERENCES}

1 Global Initiative for Asthma (GINA) workshop report. Global strategy for asthma management and prevention 2006. www.ginasthma.org/Guidelineitem.asp??11 =2\&12= $1 \&$ intId $=60$. Date last updated: November 13, 2006. Date last accessed: November 13, 2006.

2 Joos GF. Do measures of bronchial responsiveness add information in diagnosis and monitoring of patients with asthma? Eur Respir J 2001; 18: 439-441.

3 Turner SW, Palmer LJ, Rye PJ, et al. Determinants of airway responsiveness to histamine in children. Eur Respir J 2005; 25: 462-467.

4 Le Souëf PN, Geelhoed GC, Turner DJ, Morgan SE, Landau LI. Response of normal infants to inhaled histamine. Am Rev Respir Dis 1989; 139: 62-66.

5 Clarke JR, Reese A, Silverman M. Bronchial responsiveness and lung function in infants with lower respiratory tract illness over the first six months of life. Arch Dis Child 1992; 67: 1454-1458.

6 Le Souëf PN. Can measurements of airway responsiveness be standardized in children? Eur Respir J 1993; 6: 1085-1087.

7 Stick SM, Arnott J, Turner DJ, Young S, Landau LI, LeSouëf PN. Bronchial responsiveness and lung function in wheezy infants. Am Rev Respir Dis 1991; 144: 1012-1015.

8 Palmer LJ, Rye PJ, Gibson NA, Burton PR, Landau LI, Le Souëf PN. Airway responsiveness in early infancy predicts asthma, lung function, and respiratory symptoms by school age. Am J Respir Crit Care Med 2001; 163: 37-42.

9 Turner SW, Palmer LJ, Rye PJ, et al. Infants with flow limitation at 4 weeks. Outcome at 6 and 11 years. Am J Respir Crit Care Med 2002; 165: 1294-1298.

10 Saga R, Mochizuki H, Tokuyama K, Morikawa A. Relationship between bronchial hyperresponsiveness and development of asthma in wheezy infants. Chest 2001; 119: 685-690.
11 Castro-Rodríguez JA, Holberg CJ, Wright AL, Martinez FD. A clinical index to define risk of asthma in young children with recurrent wheezing. Am J Respir Crit Care Med 2000; 162: 1403-1406.

12 Malmberg LP, Pelkonen A, Hakulinen A, et al. Intraindividual variability of infant whole-body plethysmographic measurements: effects of age and disease. Pediatr Pulmonol 1999; 28: 356-362.

13 Sly PD, Tepper R, Henschen M, Gappa M, Stocks J, on behalf of the ERS/ATS Task Force on Standards for Infant Respiratory Function Testing. Tidal forced expirations. Eur Respir J 2000; 16: 741-748.

14 Hoo A-F, Dezateux C, Hanrahan JP, Cole TJ, Tepper RS, Stocks J. Sex-specific prediction equations for $V^{\prime}$ max,FRC in infancy. A multicenter collaborative study. Am J Respir Crit Care Med 2002; 165: 1084-1092.

15 Hülskamp G, Hoo A-F, Ljungberg H, Lum S, Pillow JJ, Stocks J. Progressive decline in plethysmographic lung volumes in infants. Am J Respir Crit Care Med 2003; 168: 1003-1009.

16 Sovijärvi AR, Malmberg LP, Reinikainen K, Rytilä $\mathrm{P}$, Poppius H. A rapid dosimetric method with controlled tidal breathing for histamine challenge. Repeatability and distribution of bronchial reactivity in a clinical material. Chest 1993; 104: 164-170.

17 The European Academy of Allergology and Clinical Immunology (EAACI). Position paper: allergen standardization and skin tests. Allergy 1993; 48: Suppl. 14, 48-82.

18 Benoist MR, Brouard JJ, Rufin P, Delacourt C, Waernessyckle S, Scheinmann P. Ability of new lung function tests to assess methacholine-induced airway obstruction in infants. Pediatr Pulmonol 1994; 18: 308-316.

19 James AL, Pare PD, Hogg JC. The mechanics of airway narrowing in asthma. Am Rev Respir Dis 1989; 139: 242-246.

20 Stick S. Pediatric origins of adult lung disease. 1. The contribution of airway development to paediatric and adult lung disease. Thorax 2000; 55: 587-594.

21 Saglani S, Malmström K, Pelkonen AS, et al. Airway remodelling and inflammation in symptomatic infants with reversible airflow obstruction. Am J Respir Crit Care Med 2005; 171: 722-727.

22 Prendiville A, Green S, Silverman M. Bronchial responsiveness to histamine in wheezy infants. Thorax 1987; 42: 92-99.

23 Adler A, Ngo L, Tager IB. Association of tobacco smoke exposure and respiratory syncytial virus infection with airways reactivity in early childhood. Pediatr Pulmonol 2001; 32: 418-427.

24 Godfrey S, Beardsmore CS, Maayan C, Bar-Yishay E. Can thoracic gas volume be measured in infants with airways obstruction? Am Rev Respir Dis 1986; 133: 245-251.

25 Delacourt C, Benoist M-R, Waernessyckle S, et al. Relationship between bronchial responsiveness and clinical evolution in infants who wheeze. A four-year prospective study. Am J Respir Crit Care Med 2001; 164: 1382-1386.

26 Sigurs N, Gustafsson PM, Bjarnason R, et al. Severe respiratory syncytial virus bronchiolitis in infancy and asthma and allergy at age 13. Am J Respir Crit Care Med 2005; 171: 137-141. 
27 Martinez FD, Wright AL, Taussig LM, et al. Asthma and wheezing in the first six years of life. N Engl J Med 1995; 332: 133-138.

28 Tepper RS, Rosenberg D, Eigen H. Airway responsiveness in infants following bronchiolitis. Pediatr Pulmonol 1992; 13: 6-10.

29 Young S, Le Souëf PN, Geelhoed GC, Stick SM, Turner KJ,

Landau LI. The influence of a family history of asthma and parental smoking on airway responsiveness in early infancy. N Engl J Med 1991; 324: 1168-1173.

30 Stick SM, Burton PR, Clough JB, Cox M, Le Souëf PN, Sly PD. The effects of inhaled beclomethasone dipropionate on lung function and histamine responsiveness in recurrently wheezy infants. Arch Dis Child 1995; 73: 327-332. 